\title{
Development of Fe(III)-containing ether-functionalized imidazolium ionic liquids for aryl Grignard cross-coupling of alkyl halides
}

\author{
WANG LinLin, LU Bing, ZHU AiDi, SUN HongMei* \& SHEN Qi \\ The Key Laboratory of Organic Synthesis of Jiangsu Province, College of Chemistry, Chemical Engineering and Materials Science, Soochow \\ University, Suzhou 215123, China
}

Received January 29, 2013; accepted March 14, 2013; published online May 9, 2013

\begin{abstract}
A series of $\mathrm{Fe}(\mathrm{III})$-containing imidazolium-based ionic liquids containing ether substituents, including $\left.\left[\mathrm{C}_{3} \mathrm{OMim}_{[}\right] \mathrm{FeCl}_{4}\right](\mathbf{1}$, $\left[\mathrm{C}_{3} \mathrm{OMim}\right]=1-(2-$-methoxyethyl)-3-methylimidazolium $),\left[\mathrm{C}_{3} \mathrm{O}^{i} \mathrm{Pim}\right]\left[\mathrm{FeCl}_{4}\right]\left(\mathbf{2},\left[\mathrm{C}_{3} \mathrm{O}\right.\right.$ Pim $]=1$-isopropyl-3-(2-methoxyethyl) imidazolium), $\left[\mathrm{C}_{3} \mathrm{OBim}\right]\left[\mathrm{FeCl}_{4}\right]\left(\mathbf{3},\left[\mathrm{C}_{3} \mathrm{OBim}\right]=1\right.$-butyl-3-(2-methoxyethyl)imidazolium), $\left[\left(\mathrm{C}_{3} \mathrm{O}\right)_{2} \mathrm{im}_{3}\right]\left[\mathrm{FeCl}_{4}\right]\left(\mathbf{4},\left[\left(\mathrm{C}_{3} \mathrm{O}\right)_{2} \mathrm{im}\right]=\right.$ 1,3-bis(2-methoxyethyl)imidazolium), $\left[\mathrm{C}_{3} \mathrm{OMim}\right]\left[\mathrm{FeBr}_{4}\right](\mathbf{5})$ and $\left[\left(\mathrm{C}_{3} \mathrm{O}\right)_{2} \mathrm{im}\right]\left[\mathrm{FeBr}_{4}\right](\mathbf{6})$, were prepared and characterized by elemental analysis, Raman spectroscopy and electrospray ionization mass spectrometry. The catalytic performances of 1-6 and related Fe(III)-based catalysts in the cross-coupling of aryl Grignard reagents with alkyl halides bearing $\beta$-hydrogens were studied, revealing that mono(ether) functionality improves the catalytic activity and that bis(ether) functionality improves the reusability. After simply decanting the product contained in the ethereal layer, complex $\mathbf{4}$, which containing bis(ether)-functionalized imidazolium cation, could be successfully recycled seven times.
\end{abstract}

Fe(III) complex, ether-functionalized imidazolium salt, cross-coupling, aryl Grignard reagent, alkyl halides

Citation: Wang L L, Lu B, Zhu A D, et al. Development of Fe(III)-containing ether-functionalized imidazolium ionic liquids for aryl Grignard cross-coupling of alkyl halides. Chin Sci Bull, 2013, 58: 3624-3629, doi: 10.1007/s11434-013-5838-7

During the past decade, so-called "task-specific" ionic liquids (TSILs), where the role of the ionic liquid goes beyond that of a solvent, have attracted increasing attention in a wide range of areas among the physical and chemical sciences [1].

In particular, transition metal-containing ionic liquids, where the IL acts as a ligand as well as other functions, have shown great potential in the catalysis of many organic transformations [2]. In comparison with traditional ligand supported systems, transition metal-containing ionic liquids (or so-called ionic transition metal complexes) can offer distinct advantages in terms of stability, efficiency, low toxicity and reusability, and hence offer a "green" strategy for organic synthesis [3]. In this context, increased efforts have been put towards the rational design and synthesis of functional ionic liquids through the incorporation of different functional groups, including phosphines, nitriles, pyridines, amines, ethers, alcohols, and acids, as a part of the

*Corresponding author (email: sunhm@ suda.edu.cn) imidazolium cation [4,5]. Such incorporation is believed to improve metal ion immobilization, thereby increasing the reaction rate, selectivity and/or improving catalyst retention [6,7]. For example, Dyson and co-workers [8] showed that ether-func-tionalized imidazolium salts promote palladiumcatalyzed Suzuki cross-coupling reactions, and proposed that increase came from the weak interactions between the ether moiety and the palladium active species. In addition, two Pd(II)-containing ILs were synthesized for the first time via the reaction of $\mathrm{PdCl}_{2}$ with the corresponding etherfunctional-ized imidazolium salt [8].

In a continuation of our work focused on the development of Fe(III)-containing imidazolium ILs for use in the cross-coupling of aryl Grignard reagents with alkyl halides [9-12], we report here on the use of ether-functionalized imidazolium salts in the facile synthesis of a series of $\mathrm{Fe}(\mathrm{III})$-containing ILs 1-6, and their use as catalysts in cross-coupling the aryl Grignard with alkyl halides with $\beta$-hydrogens. Ether-functionalized imidazolium salts have 
demonstrated attractive physicochemical properties for particular applications, e.g. tunable solvent properties that improve their usefulness as reaction solvents or organocatalysts [13]. However, to the best of our knowledge, they have not been used as ligands in the preparation of iron-based catalysts, despite the increased interest in iron catalysis for a variety of cross-coupling reactions $[14,15]$ and the possibility that the presence of a ether group might help stabilize the catalytic active species via weak interactions, thereby increasing output and/or improving recyclability.

\section{Experimental}

Since anhydrous $\mathrm{FeCl}_{3}, \mathrm{FeBr}_{3},\left[\mathrm{C}_{3} \mathrm{OMim}\right] \mathrm{Cl}\left(\mathbf{a},\left[\mathrm{C}_{3} \mathrm{OMim}\right]=\right.$ 1-(2-methoxyethyl)-3-methylimidazolium), $\left[\mathrm{C}_{3} \mathrm{O}^{i} \mathrm{Pim}\right] \mathrm{Cl}$ (b, $\left[\mathrm{C}_{3} \mathrm{O}\right.$ Pim $]=1$-isopropyl-3-(2-methoxyethyl)imidazolium), $\left[\mathrm{C}_{3} \mathrm{OBim}\right] \mathrm{Cl}$ (c, $\left[\mathrm{C}_{3} \mathrm{OBim}\right]=1$-butyl-3-(2-methoxyethyl) imidazolium), and $\left[\left(\mathrm{C}_{3} \mathrm{O}\right)_{2} \mathrm{im}\right] \mathrm{Cl}\left(\mathbf{d},\left[\left(\mathrm{C}_{3} \mathrm{O}\right)_{2} \mathrm{im}\right]=1,3\right.$-bis $(2-$ methoxyethyl)imidazolium) are hydrophilic, all manipulations were carried out under an atmosphere of dry argon with rigorous exclusion of air and moisture using Schlenk techniques.

\subsection{Materials}

All organic solvents were freshly distilled from Na/benzophenone ketyl under pure argon prior to use. Anhydrous $\mathrm{FeCl}_{3}, \mathrm{FeBr}_{3}$ and organic reagents used for cross-coupling reactions were bought from Acros Organics, Aldrich, and Alfa Aesar. ArMgX was diluted prior to use. Ether-functionalized imidazolium salts a [16] and d [17] were prepared by the established methods.

\subsection{Synthesis}

(i) Synthesis of $\left[\mathrm{C}_{3} \mathrm{O}^{i} \mathrm{Pim}\right] \mathrm{Cl}(\mathbf{b})$. Following a procedure similar to the synthetic procedure of a [16], a Schlenk flask was charged with $N$-isopropylimidazole (55 g, $0.5 \mathrm{~mol}$ ), 2-chloroethyl methyl ether (47 g, $0.5 \mathrm{~mol})$ and a stirring bar. The reaction mixture was stirred for $48 \mathrm{~h}$ at $80^{\circ} \mathrm{C}$. The mixture was washed with ethyl acetate and dried in vacuo. The product was obtained as light yellow oil in $78 \%$ yield $(80 \mathrm{~g})$. ${ }^{1} \mathrm{H}$ NMR $\left(\mathrm{CDCl}_{3}\right): \delta 10.58(\mathrm{~s}, 1 \mathrm{H}, \mathrm{NCHN}), 7.51(\mathrm{~s}, 1 \mathrm{H}, \mathrm{CH})$, $7.45(\mathrm{~s}, 1 \mathrm{H}, \mathrm{CH}), 4.80(\mathrm{~m}, 1 \mathrm{H}, \mathrm{CH}), 4.58(\mathrm{t}, J=4.6 \mathrm{~Hz}, 2 \mathrm{H}$, $\left.\mathrm{CH}_{2}\right), 3.73$ (t, $\left.\mathrm{J}=4.6 \mathrm{~Hz}, 2 \mathrm{H}, \mathrm{CH}_{2}\right), 3.31\left(\mathrm{~s}, 3 \mathrm{H}, \mathrm{CH}_{3}\right), 1.56$ $\left(\mathrm{d}, J=6.4 \mathrm{~Hz}, 6 \mathrm{H}, 2 \times \mathrm{CH}_{3}\right) .{ }^{13} \mathrm{C} \mathrm{NMR}\left(\mathrm{CDCl}_{3}\right): \delta 22.86$, 49.31, 52.86, 58.69, 70.19, 119.54, 123.08, 135.86. MS (ESI+): $m / z, 169.1333\left[\mathrm{C}_{9} \mathrm{H}_{17} \mathrm{~N}_{2} \mathrm{O}\right]^{+}(100 \%)$.

(ii) Synthesis of $\left[\mathrm{C}_{3} \mathrm{OBim}\right] \mathrm{Cl}(\mathbf{c})$. The same procedure was followed as that described above for $\mathbf{b}$, except for the use of 1- $n$-butylimidazole $(62 \mathrm{~g}, 0.5 \mathrm{~mol})$ instead of 1-isopropylimidazole. The product $(82 \mathrm{~g}, 75 \%)$ was obtained as a slightly yellow oil. ${ }^{1} \mathrm{H} \mathrm{NMR}\left(\mathrm{CDCl}_{3}\right): \delta=10.49(\mathrm{~s}, 1 \mathrm{H}$, $\mathrm{NCHN}), 7.53$ (s, 1H, CH), 7.39 (s, 1H, CH), 4.57 (t, J = 4.8
$\left.\mathrm{Hz}, 2 \mathrm{H}, \mathrm{CH}_{2}\right), 4.26\left(\mathrm{t}, J=7.4 \mathrm{~Hz}, 2 \mathrm{H}, \mathrm{CH}_{2}\right), 3.71(\mathrm{t}, J=4.8$ $\left.\mathrm{Hz}, 2 \mathrm{H}, \mathrm{CH}_{2}\right), 3.29$ (s, 3H, $\left.\mathrm{CH}_{3}\right), 1.84\left(\mathrm{~m}, 2 \mathrm{H}, \mathrm{CH}_{2}\right), 1.31$ $\left(\mathrm{m}, 2 \mathrm{H}, \mathrm{CH}_{2}\right), 0.89\left(\mathrm{t}, J=7.4 \mathrm{~Hz}, 3 \mathrm{H}, \mathrm{CH}_{3}\right) .{ }^{13} \mathrm{C} \mathrm{NMR}$ $\left(\mathrm{CDCl}_{3}\right): \delta 13.12,19.09,31.76,49.24,49.35,58.61,70.06$, 121.57, 122.96, 136.77. MS (ESI+): $\mathrm{m} / z \quad 183.1494$ $\left[\mathrm{C}_{10} \mathrm{H}_{19} \mathrm{~N}_{2} \mathrm{O}\right]^{+}(100 \%)$.

(iii) Synthesis of $\left[\mathrm{C}_{3} \mathrm{OMim}\right]\left[\mathrm{FeCl}_{4}\right](\mathbf{1})$. A Schlenk flask was charged with $\left[\mathrm{C}_{3} \mathrm{OMim}\right] \mathrm{Cl}(1.77 \mathrm{~g}, 10.00 \mathrm{mmol})$, THF $(15 \mathrm{~mL})$ and a stirring bar. To this suspension, $\mathrm{FeCl}_{3}(1.62 \mathrm{~g}$, $10.00 \mathrm{mmol}$ ) in $15 \mathrm{~mL}$ of THF was added. The reaction mixture was stirred for $6 \mathrm{~h}$ at room temperature, filtered and evaporated to dryness. The residue was washed with mixed $\mathrm{THF} /$ hexane $(\mathrm{v} / \mathrm{v}=1: 10)$ and dried in vacuo. The product was obtained as yellow-green oil in $93 \%$ yield $(3.15 \mathrm{~g})$. Anal. Calcd. for $\mathrm{C}_{7} \mathrm{H}_{13} \mathrm{~N}_{2} \mathrm{OFeCl}_{4}(\%)$ : C, 24.78; $\mathrm{H}, 3.83 ; \mathrm{N}$, 8.26. Found: C, 24.63; H, 3.73; N, 8.35. MS (ESI+): $\mathrm{m} / \mathrm{z}$ $141.1030\left[\mathrm{C}_{7} \mathrm{H}_{13} \mathrm{~N}_{2} \mathrm{O}\right]^{+}(100 \%)$. Raman spectrum: $337 \mathrm{~cm}^{-1}$ $\left(\left[\mathrm{FeCl}_{4}\right]^{-}\right)$.

(iv) Synthesis of $\left[\mathrm{C}_{3} \mathrm{O}^{i} \mathrm{Pim}\right]\left[\mathrm{FeCl}_{4}\right]$ (2). Following a procedure similar to the synthetic procedure of $\mathbf{1}$, where using $\left[\mathrm{C}_{3} \mathrm{O}^{i} \mathrm{Pim}\right] \mathrm{Cl}(2.05 \mathrm{~g}, 10.00 \mathrm{mmol})$ as the starting materials, the product $2(3.30 \mathrm{~g}, 90 \%)$ was obtained as a yellow-green oil. Anal. Calcd. for $\mathrm{C}_{9} \mathrm{H}_{17} \mathrm{~N}_{2} \mathrm{OFeCl}_{4}(\%)$ : C, 29.43; $\mathrm{H}, 4.63$; N, 7.63. Found: C, 29.45; H, 4.77; N, 7.54. MS (ESI+): $\mathrm{m} / \mathrm{z}$ $169.1332\left[\mathrm{C}_{9} \mathrm{H}_{17} \mathrm{~N}_{2} \mathrm{O}\right]^{+}(100 \%)$. Raman spectrum: $336 \mathrm{~cm}^{-1}$ $\left(\left[\mathrm{FeCl}_{4}\right]^{-}\right)$.

(v) Synthesis of $\left[\mathrm{C}_{3} \mathrm{OBim}\right]\left[\mathrm{FeCl}_{4}\right](3)$. Following a procedure similar to the synthetic procedure of $\mathbf{1}$, where using $\left[\mathrm{C}_{3} \mathrm{OBim}\right] \mathrm{Cl}(2.19 \mathrm{~g}, 10.00 \mathrm{mmol})$ as the starting material, the product $3(3.24 \mathrm{~g}, 85 \%)$ was obtained as a yellow-green oil. Anal. Calcd. for $\mathrm{C}_{10} \mathrm{H}_{19} \mathrm{~N}_{2} \mathrm{OFeCl}_{4}(\%)$ : C, 31.50; H, 4.99; N, 7.35. Found: C, 31.20; H, 4.89; N, 7.41. MS (ESI+): $\mathrm{m} / \mathrm{z}$ $183.1503\left[\mathrm{C}_{10} \mathrm{H}_{19} \mathrm{~N}_{2} \mathrm{O}\right]^{+}(100 \%)$. Raman spectrum: $333 \mathrm{~cm}^{-1}$ $\left(\left[\mathrm{FeCl}_{4}\right]^{-}\right)$.

(vi) Synthesis of $\left[\left(\mathrm{C}_{3} \mathrm{O}\right)_{2} \mathrm{im}\right]\left[\mathrm{FeCl}_{4}\right]$ (4). Following a procedure similar to the synthetic procedure of $\mathbf{1}$, where using $\left[\left(\mathrm{C}_{3} \mathrm{O}\right)_{2} \mathrm{im}\right] \mathrm{Cl}(2.21 \mathrm{~g}, 10.00 \mathrm{mmol})$ as the starting material, the product $4(3.45 \mathrm{~g}, 90 \%)$ was obtained as a yellow-green oil. Anal. Calcd. for $\mathrm{C}_{9} \mathrm{H}_{17} \mathrm{~N}_{2} \mathrm{O}_{2} \mathrm{FeCl}_{4}(\%)$ : C, 28.20; H, 4.44; N, 7.31. Found: C, 28.13; H, 4.19; N, 7.32. MS (ESI+): $m / z \quad 185.1294\left[\mathrm{C}_{9} \mathrm{H}_{17} \mathrm{~N}_{2} \mathrm{O}_{2}\right]^{+}(100 \%)$. Raman spectrum: $334 \mathrm{~cm}^{-1}\left(\left[\mathrm{FeCl}_{4}\right]^{-}\right)$.

(vii) Synthesis of $\left[\mathrm{C}_{3} \mathrm{OMim}\right]\left[\mathrm{FeBr}_{4}\right](5)$. A Schlenk flask was charged with $\left[\mathrm{C}_{3} \mathrm{OMim}\right] \mathrm{Cl}(1.76 \mathrm{~g}, 10.00 \mathrm{mmol}), \mathrm{NaBr}$ (1.54 g, $15.00 \mathrm{mmol})$, THF (25 mL) and a stirring bar. To this suspension, $\mathrm{FeBr}_{3}(2.96 \mathrm{~g}, 10.00 \mathrm{mmol})$ in $15 \mathrm{~mL}$ of THF was added. The reaction mixture was stirred for $24 \mathrm{~h}$ at $60^{\circ} \mathrm{C}$, filtered and evaporated to dryness. The residue was washed with mixed $\mathrm{THF} / \mathrm{hexane}(\mathrm{v} / \mathrm{v}=1: 10)$ and dried in vacuo. The product was obtained as brown-red oil in $80 \%$ yield (4.13g). Anal. Calcd. for $\mathrm{C}_{7} \mathrm{H}_{13} \mathrm{~N}_{2} \mathrm{OFeBr}_{4}(\%)$ : C, 16.25; $\mathrm{H}, 2.51 ; \mathrm{N}, 5.42$. Found: $\mathrm{C}, 15.85 ; \mathrm{H}, 2.62 ; \mathrm{N}, 5.63$. MS (ESI+): $m / z \quad 141.1022 \quad\left[\mathrm{C}_{7} \mathrm{H}_{13} \mathrm{~N}_{2} \mathrm{O}\right]^{+} \quad(100 \%)$. Raman spectrum: $204 \mathrm{~cm}^{-1}\left(\left[\mathrm{FeBr}_{4}\right]^{-}\right)$.

(viii) Synthesis of $\left[\left(\mathrm{C}_{3} \mathrm{O}\right)_{2} \mathrm{im}\right]\left[\mathrm{FeBr}_{4}\right](\mathbf{6})$. Following a 
procedure similar to the synthetic procedure of $\mathbf{5}$, where using $\left[\left(\mathrm{C}_{3} \mathrm{O}\right)_{2} \mathrm{im}\right] \mathrm{Cl}(2.21 \mathrm{~g}, 10.00 \mathrm{mmol})$ as the starting material, the product $6(4.94 \mathrm{~g}, 88 \%)$ was obtained as a brown-red oil. Anal. Calcd. for $\mathrm{C}_{9} \mathrm{H}_{17} \mathrm{~N}_{2} \mathrm{O}_{2} \mathrm{FeBr}_{4}(\%)$ : C, 19.25; H, 3.03; N, 4.99. Found: C, 19.52; H, 3.14 N, 4.85. MS (ESI+): $m / z \quad 185.1297\left[\mathrm{C}_{9} \mathrm{H}_{17} \mathrm{~N}_{2} \mathrm{O}_{2}\right]^{+}$(100\%). Raman spectrum: $203 \mathrm{~cm}^{-1}\left(\left[\mathrm{FeBr}_{4}\right]^{-}\right)$.

(ix) Typical cross-coupling procedure. A Schlenk tube was charged with an Fe(III)-based catalyst (0.02 mmol), alkyl bromide $(1.00 \mathrm{mmol}), n$-hexadecane $(0.10 \mathrm{mmol})$ as internal standard, diethyl ether $(1.60 \mathrm{~mL})$ and a stirring bar. 4-Methylphenylmagnesium bromide $(1.40 \mathrm{~mL}, 1.20 \mathrm{mmol})$ was added to this solution at room temperature. The resulting solution turned black immediately and was then stirred for $10 \mathrm{~min}$ at room temperature. After the reaction was quenched by addition of saturated ammonium chloride solution, the mixture was extracted with diethyl ether $(3 \times 3 \mathrm{~mL})$ and dried over $\mathrm{Na}_{2} \mathrm{SO}_{4}$. The $\mathrm{GC}$ yield of the desired product is determined by GC analysis, using $n$-hexadecane as an internal standard.

Purification of the crude mixture by flash column chromatography (silica gel, 5.0\% ethyl acetate/pet ether (60$\left.90^{\circ} \mathrm{C}\right)$ ) gave the isolated yield of the desired coupling product. The identity of the product was confirmed by ${ }^{1} \mathrm{H}$ NMR spectroscopy and TLC.

\subsection{Analyses}

Carbon, hydrogen, and nitrogen analyses were preformed by direct combustion with a Carlo-Erba EA-1110 instrument. The Raman spectra were recorded on a LabRAM HR800 spectrometer. Electrospray ionization-mass spectrum (ESI-MS) data were recorded on a 6220 AccurateMass TOF LC/MS instrument. Gas chromatographic (GC) analysis was performed on a Varian CP-3800 instrument equipped with a flame ionization detector and a OV-101 capillary column $(30 \mathrm{~m} \times 0.32 \mathrm{~mm}$ (i.d.), $0.10 \mu \mathrm{m}$ film). The oven temperature was held at $80^{\circ} \mathrm{C}$ for $2 \mathrm{~min}$, increased to $280^{\circ} \mathrm{C}$ at $10^{\circ} \mathrm{C} / \mathrm{min}$, and held for $2 \mathrm{~min}$.

\section{Results and discussion}

\subsection{Synthesis and characterization of Fe(III)-containing ILs}

The structures of the ether-functionalized imidazolium salts prepared and used in the present work are shown in Figure 1.

The mono(ether)-functionalized imidazolium salt $\left[\mathrm{C}_{3} \mathrm{O}\right.$ $\mathrm{Mim}] \mathrm{Cl}$ (a) [16] and the bis(ether)-functionalized imidazolium salt $\left[\left(\mathrm{C}_{3} \mathrm{O}\right)_{2} \mathrm{im}\right] \mathrm{Cl}$ (d) [17] have been reported previously. New mono(ether)-functionalized imidazolium salts $\left[\mathrm{C}_{3} \mathrm{O}^{i} \mathrm{Pim}\right] \mathrm{Cl}(\mathbf{b})$ and $\left[\mathrm{C}_{3} \mathrm{OBim}\right] \mathrm{Cl}(\mathbf{c})$ were easily prepared via the simple quaternization reaction between 2-chloroethyl methyl ether and the corresponding $N$-hydrocarbylimidazole, similarly to the published procedure of the

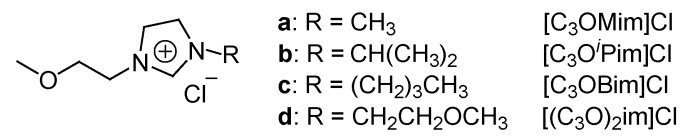

Figure 1 Ether-functionalized imidazolium salts.

chloride salt a [16], in yields of $78 \%$ and $75 \%$, respectively (Scheme 1). The salts $\mathbf{b}$ and $\mathbf{c}$ are light yellow viscous liquids. They were characterized by NMR spectroscopy and electrospray ionization mass spectroscopy (ESI-MS). The most significant features of the ${ }^{1} \mathrm{H}$ NMR spectra of $\mathbf{b}$ and $\mathbf{c}$ were the signals assigned to the imidazolium protons (C2-H), appearing at 10.58 and 10.49, respectively [16]. The positive ion ESI-MS spectra of $\mathbf{b}$ and $\mathbf{c}$ were used to establish the presence of the mono(ether)-functionalized imidazolium cations, and in each case a high relative intensity peak, indicating the parent cation, was observed.

The salts a-d react with $\mathrm{FeCl}_{3}$ in a $1: 1$ molar ratio at room temperature to form the corresponding $\mathrm{Fe}(\mathrm{III})$-containing ILs $\left[\mathrm{C}_{3} \mathrm{OMim}\right]\left[\mathrm{FeCl}_{4}\right]$ (1), $\left[\mathrm{C}_{3} \mathrm{O}^{i} \mathrm{Pim}\right]\left[\mathrm{FeCl}_{4}\right]$ (2), $\left[\mathrm{C}_{3} \mathrm{OBim}\right]\left[\mathrm{FeCl}_{4}\right](3)$, and $\left[\left(\mathrm{C}_{3} \mathrm{O}\right)_{2} \mathrm{im}\right]\left[\mathrm{FeCl}_{4}\right](\mathbf{4})$ as yellowgreen oils in almost quantitative yields, as outlined in Scheme 2.

Exchanging the $\left[\mathrm{FeCl}_{4}\right]^{-}$anion for the $\left[\mathrm{FeBr}_{4}\right]^{-}$anion also proceeded smoothly by adding sodium bromide ( $\mathrm{NaBr}$ ). As seen in Scheme 3, the treatment of the chloride salts $\mathbf{a}$ and $\mathbf{b}$ with 1 equiv of $\mathrm{FeBr}_{3}$ in the presence of excess $\mathrm{NaBr}$ afforded the bromides $\left[\mathrm{C}_{3} \mathrm{OMim}\right]\left[\mathrm{FeBr}_{4}\right](\mathbf{5})$ and $\left[\left(\mathrm{C}_{3} \mathrm{O}\right)_{2}\right.$ $\mathrm{im}]\left[\mathrm{FeBr}_{4}\right](\mathbf{6})$ as brown-red oils in high yields. These reactions, however, proceeded at slower rates than those presented in Scheme 2, mostly because of the poor solubility of $\mathrm{NaBr}$ in $\mathrm{THF}$, and thus an extended reaction time $(24 \mathrm{~h})$ and an elevated temperature $\left(60^{\circ} \mathrm{C}\right)$ were required to push the reaction to completion.

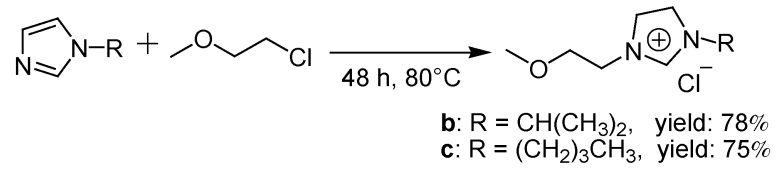

Scheme 1 Synthesis of the mono(ether)-functionalized imidazolium salts b and c.

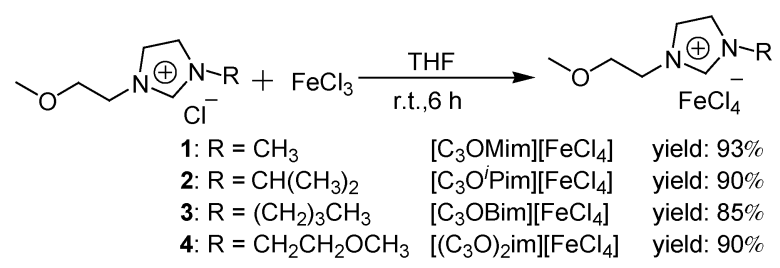

Scheme 2 Synthesis of the Fe(III)-containing ILs 1-4.

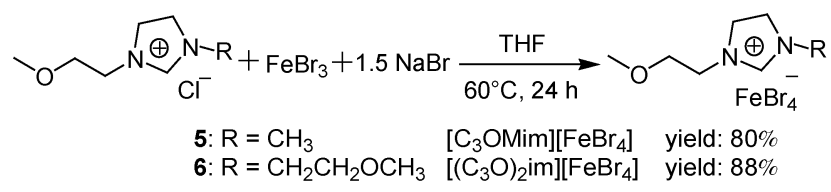

Scheme 3 Synthesis of the Fe(III)-containing ILs 5-6 
Interestingly, complexes 1-6 are non-hygroscopic and air-stable, despite $\mathrm{FeCl}_{3}$ and $\mathrm{FeBr}_{3}$ being highly hygroscopic.

The formation of complexes 1-6 was supported by elemental analysis, Raman spectroscopy and ESI-MS. The Raman spectra of 1-4 and 5-6 are shown in Figure 2. The largest feature of the Raman spectra of 1-4 is one strong peak at the range of $333-337 \mathrm{~cm}^{-1}$, while the one strong peak was present at $c a .203 \mathrm{~cm}^{-1}$ in the spectra of 5 and $\mathbf{6}$. These data coincide very closely to the literature values for the $\left[\mathrm{FeCl}_{4}\right]^{-}$and $\left[\mathrm{FeBr}_{4}\right]^{-}$species [18]. The positive ion ESIMS spectra of 1-6 were used to establish the presence of the mono(ether)- or bis(ether)-functionalized imidazolium cations, and in all cases a peak with an intensity of almost $100 \%$, indicating the parent cation, was observed. Therefore, these characteristic results confirmed that complexes 1-6 consist of one imidazolium cation and one $\left[\mathrm{FeX}_{4}\right]^{-}$anion.

\subsection{Catalysis with Fe(III)-containing ILs}

During the past decade the development of well-defined iron complexes for the cross-coupling reaction of aryl Grignard reagents with alky halides has received increasing attention, mostly because of their ability to suppress the undesired $\beta$-hydrogen elimination as well as their potentiality with a mechanistic point of view $[9,19]$. For example, an $\mathrm{Fe}(\mathrm{III})$-containing IL $[\mathrm{BMim}]\left[\mathrm{FeCl}_{4}\right](\mathrm{BMim}=1$-butyl-3methylimidazolium) has been highly active for this reaction [20]. Therefore, the reaction outlined in eq. (1) was chosen as a prototype cross-coupling of aryl Grignard reagents with alkyl halides bearing $\beta$-hydrogens [20] to assess the catalytic activity of 1-6. The results obtained are listed in Table 1 .

This cross-coupling reaction could be performed at room temperature, and the Grignard reagent was added in a single portion without the requirement for slow addition via a syringe pump. As can be seen from Table 1, all of the catalysts provided good to excellent yields of the desired coupling
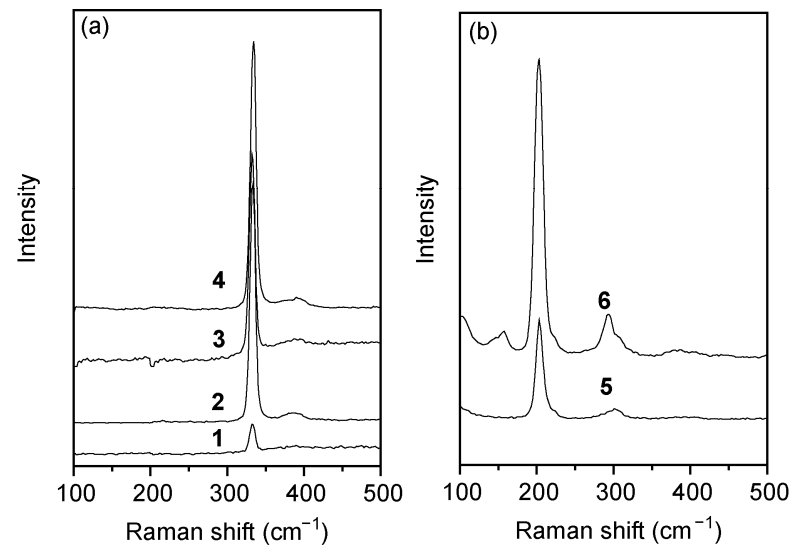

Figure 2 Raman spectra of 1-4 (a) and 5-6 (b).

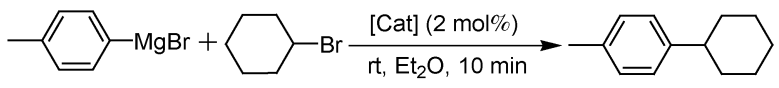

Table 1 Activities of catalytic systems based on Fe(III) complexes ${ }^{\text {a) }}$

\begin{tabular}{ccc||ccc}
\hline Entry & \multicolumn{1}{c}{ Catalyst } & $\begin{array}{c}\text { Yield } \\
(\%)\end{array}$ & Entry & Catalyst & $\begin{array}{c}\text { Yield } \\
(\%)\end{array}$ \\
\hline 1 & $\mathrm{FeCl}_{3}$ & 16 & 6 & $\mathbf{3}$ & 91 \\
2 & {$\left[\mathrm{C}_{3} \mathrm{OMim}\right] \mathrm{Cl}$} & 0 & 7 & $\mathbf{4}$ & 92 \\
3 & $\mathrm{FeCl}_{3}+\left[\mathrm{C}_{3} \mathrm{OMim}\right] \mathrm{Cl}$ & 59 & 8 & $\mathbf{5}$ & 89 \\
4 & $\mathbf{1}$ & $98\left(87^{\text {b) }}\right.$, & 9 & $\mathbf{6}$ & 87 \\
& & $\left.89^{\text {b,c) }}\right)$ & 10 & {$\left[\mathrm{BMim}_{[}\right]\left[\mathrm{FeCl}_{4}\right]$} & 80 \\
5 & $\mathbf{2}$ & 98 & & & \\
\hline
\end{tabular}

a) Reaction conditions: Catalyst $(2.0 \mathrm{~mol} \%), 4-\mathrm{MeC}_{6} \mathrm{H}_{4} \mathrm{MgBr}(1.2 \mathrm{mmol})$ was added in one portion, cyclohexyl bromide $(1.0 \mathrm{mmol}), \mathrm{Et}_{2} \mathrm{O}$, total volume $(3.0 \mathrm{~mL})$, room temperature, $10 \mathrm{~min}$, Ar, GC yield using $n$-hexadecane as internal standard, average of 2 trials. b) Isolated yield. c) In air.

product (Table 1, entries 4-9), with 1 and $\mathbf{2}$ exhibiting the highest activity (Table 1, entries 4-5). The data from 1-4 did not show an obvious trend from either the electronic or steric nature of the $N$-substituent on the ether-functionalized imidazole ring. The small differences in activity between 1, 2, 5 and $\mathbf{6}$ show that replacing the $\left[\mathrm{FeCl}_{4}\right]^{-}$anion with $\left[\mathrm{FeBr}_{4}\right]^{-}$was slightly detrimental to performance. Interestingly, a mixture of $\mathrm{FeCl}_{3}$ and $\left[\mathrm{C}_{3} \mathrm{OMim}\right] \mathrm{Cl}$ in a $1: 1$ molar ratio exhibited moderate activity under the same conditions, and provided the coupling product in 59\% yield (Table 1, entry 3 ). In comparison, $\mathrm{FeCl}_{3}$ alone afforded the product at a significantly low yield (Table 1, entry 1 ). These results suggest that the imidazolium cations presented in 1-4 played a key role during the catalytic process, mostly relying on in situ deprotonation of the imidazolium cation by the Grignard reagent to yield the $N$-heterocyclic carbene (NHC) ligands [21]. The reaction also proceeds smoothly without an inert atmosphere, and there was no obvious difference between the use of an air atmosphere or pure argon (Table 1, entry 4). Furthermore, the catalytic activity of $\mathbf{1}$ was compared with $\left[\mathrm{BMim}^{-}\left[\mathrm{FeCl}_{4}\right]\right.$, a $\mathrm{Fe}(\mathrm{III})$-containing IL based on a non-functionalized imidazolium cation reported previously [20]. $\left[\mathrm{C}_{3} \mathrm{OMim}\right]\left[\mathrm{FeCl}_{4}\right]$ shows superior performance under identical conditions (compare entries 1 and 10).

To evaluate the influence of the cationic component of 1-4 in detail, we next examined the recyclability of the complexes $\mathbf{1}$ and $\mathbf{4}$ in the prototype cross-coupling reaction outlined in eq. (1). Similar to a published procedure [10,20], when the reaction was performed with $5 \mathrm{~mol} \%$ of $\mathbf{1}$ or $\mathbf{4}$, the upper ether layer containing the product was decanted after the reaction was complete. The catalytic active species [22] was left in the black sediment, washed twice with $0.5 \mathrm{~mL}$ of diethyl ether and evaporated to dryness. A diethyl ether solution of fresh cyclohexyl bromide was added to the residual catalyst. Successive addition of Grignard reagent initiated the next catalytic cycle.

The data listed in Table 2 indicated that complex 4 could be reused in at least seven successive runs of the model reaction, with cyclohexyl bromide being almost completed consumed. The GC yield of desired coupling product, however, gradually dropped from $98 \%$ in the first run to $88 \%$ in the seventh run (Table 2, entries 1-7). This may be because 
Table 2 Recycling of $\mathbf{1}$ and 4 in the cross-coupling of $4-\mathrm{MeC}_{6} \mathrm{H}_{4} \mathrm{MgBr}$ with $\mathrm{C}_{6} \mathrm{H}_{11} \mathrm{Br}^{\text {a) }}$

\begin{tabular}{cccccc}
\hline Entry & Run & Conv. $(\%)^{\mathrm{b})}$ & ${\text { Yield }(\%)^{\mathrm{b})}}$ & Conv. $(\%)^{\mathrm{c})}$ & ${\text { Yield }(\%)^{\mathrm{c})}}$ \\
\hline 1 & 1 & $>99$ & 99 & $>99$ & 98 \\
2 & 2 & $>99$ & 95 & $>99$ & 97 \\
3 & 3 & 98 & 97 & 98 & 97 \\
4 & 4 & 95 & 90 & 97 & 95 \\
5 & 5 & 57 & 45 & 99 & 96 \\
6 & 6 & - & - & 99 & 92 \\
7 & 7 & - & - & 94 & 88 \\
\hline
\end{tabular}

a) Reaction conditions, 4- $\mathrm{MeC}_{6} \mathrm{H}_{4} \mathrm{MgBr}(1.2 \mathrm{mmol})$ was added in one portion, cyclohexyl bromide $(1.0 \mathrm{mmol}), \mathrm{Et}_{2} \mathrm{O}$ total volume $(3 \mathrm{~mL})$, room temperature, $10 \mathrm{~min}$, Ar, GC yield using $n$-hexadecane as internal standard. b) Catalyst $1(5.0 \mathrm{~mol} \%)$. c) Catalyst 4 (5.0 mol\%). of catalyst leaching during the decanting and extraction steps [20]. The recycling experiments with $\mathbf{1}$, however, led to a considerable decrease in the GC yield from $99 \%$ in the first run, to $45 \%$ in the fifth run, similar to that of nonfunctionalized $[\mathrm{bmim}]\left[\mathrm{FeCl}_{4}\right][20]$. Therefore, the present work demonstrated that the modification of imidazole ring with ether group not only benefits the catalytic activity, but also improves the recycling of the $\mathrm{Fe}(\mathrm{III})$-based catalysts. The significantly greater recyclability of $\mathbf{4}$ over that of $\mathbf{1}$ shows the importance of the bis(ether) functionality in the reusability of the catalyst, which may be due to the weak interaction derived from the two ether groups.

Substrate screening was subsequently carried out, and the results obtained are summarized in Table 3 .

Table 3 Results of various aryl Grignard cross-couplings catalyzed by $\mathbf{1}^{\text {a) }}$

\begin{tabular}{|c|c|c|c|c|}
\hline Entry & Alkyl halide & $\mathrm{ArMgBr}$ & Product & Yield (\%) \\
\hline 1 & & $-\mathrm{Mc}$ & & $98\left(92^{b)}\right)$ \\
\hline 2 & & $-M$ & & 95 \\
\hline 3 & & & & 85 \\
\hline 4 & & & & 70 \\
\hline 5 & & & & 78 \\
\hline 6 & & $-\mathrm{Ms}$ & & 81 \\
\hline 7 & & $-\mathrm{Ms}$ & & 88 \\
\hline 8 & & & & $72^{c)}$ \\
\hline 9 & & & & $70^{\text {d) }}$ \\
\hline 10 & & & & $52^{\mathrm{d})}$ \\
\hline 11 & & & & $80^{\text {d) }}$ \\
\hline 12 & & & & $82^{\text {d) }}$ \\
\hline 13 & & & & $42^{c)}$ \\
\hline 14 & $\mathrm{Br}$ & & & $76^{\text {d) }}$ \\
\hline 15 & $\mathrm{Br}$ & & & $69^{\text {d) }}$ \\
\hline 16 & & & & $33^{\text {c) }}$ \\
\hline 17 & $n-\mathrm{C}_{8} \mathrm{H}_{17}-\mathrm{Br}$ & & & $68^{\text {d) }}$ \\
\hline 18 & $n-\mathrm{C}_{8} \mathrm{H}_{17}-\mathrm{Cl}$ & & & $17^{\text {c) }}$ \\
\hline
\end{tabular}

a) Reaction conditions: Catalyst $1(2.0 \mathrm{~mol} \%), \mathrm{ArMgX}(1.2 \mathrm{mmol})$ was added in one portion, alkyl halide $(1.0 \mathrm{mmol}), \mathrm{Et}_{2} \mathrm{O}$ total volume $(3 \mathrm{~mL})$, room temperature, $10 \mathrm{~min}$, Ar, GC yield using $n$-hexadecane as internal standard, average of 2 trials. b) Isolated yield. c) $\mathrm{ArMgX}(1.5 \mathrm{mmol}), 30 \mathrm{~min} . \mathrm{d}) 30 \mathrm{~min}$. 
As can be seen from Table 3, a large number of arylmagnesium halides reacted smoothly with various alkyl bromides and chlorides to give the corresponding coupling products in good to excellent yields. Comparing the results from the aryl Grignard reagents used in the reaction with cyclohexyl bromide (entries 1-6) indicates that the electronrich aryl Grignard reagents react rapidly to give the desired product (Table 3, entries 1 and 2), whereas reagents with electron-withdrawing groups react more sluggishly (entry 6). Changing the Grignard reagent to the less reactive phenylmagnesium chloride still gave a smooth reaction, but in lower yield (70\%, Table 3, entry 4). Steric hindrance is partially tolerated by the system as demonstrated by $o$-tolylmagnesium bromide, giving a reduced yield of $78 \%$ (Table 3 , entry 5). Comparing entries 1,7 and 8 showed the desired product is obtained in better yield when cyclohexyl bromide was used, and the general trend appears to be $\mathrm{R}-\mathrm{Br}>\mathrm{R}-\mathrm{I}>\mathrm{R}-\mathrm{Cl}$. This was the same pattern as that previously reported for $[\mathrm{bmim}]\left[\mathrm{FeCl}_{4}\right][20]$ and related $\mathrm{Fe}(\mathrm{III})$ containing ILs [11]. Changing the cycloalkyl bromide to cyclopentyl bromide or cycloheptyl bromide yielded the desired product but in lower yields of $70 \%$ and $52 \%$, respectively, with an extended reaction time (Table 3, entries 9 and 10). The current Fe(III)-catalyzed cross-coupling was applicable to other secondary or primary alkyl bromides, ever to less reactive alkyl chlorides (Table 3, entries 13, 16 and 18). Therefore, these results suggest the great potential of the new type $\mathrm{Fe}$ (III)-containing ILs as suitable catalyst for $\mathrm{C}-\mathrm{C}$ cross-coupling applications.

\section{Conclusions}

Novel Fe(III)-containing ILs of ether-functionalized imidazolium cations (1-6) have been easily synthesized and showed great potential as efficient catalysts for the crosscoupling of aryl Grignard reagents with primary and secondary alkyl halides bearing $\beta$-hydrogens under mild conditions. Moreover, complex $\mathbf{4}$ could be reused seven times without any significant loss in catalytic activity. Since a variety of imidazolium cations bearing ether functionalities are readily available, i.e. through the simple quaternization of an imidazole ring with oxygen-containing alkyl halides, we believe that this modification of the imidazole ring can be used as an alternative strategy for the design and synthesis of highly active and recyclable catalytic systems. Further work directed at a detailed structure-reactivity relationship study of this new type of Fe(III)-containing ILs, and the scope of these $\mathrm{Fe}(\mathrm{III})$-containing ILs in other carbon-carbon coupling reactions is currently underway in our laboratory.

This work was supported by the National Natural Science Foundation of China (21172164), the Key Laboratory of Organic Chemistry of Jiangsu
Province, and the Priority Academic Program Development of Jiangsu Higher Education Institutions (PAPD).

1 Giernoth R. Task-specific ionic liquids. Angew Chem Int Ed, 2010, 49: 2834-2839

2 Olivier-Bourbigou H, Magna L, Morvan D. Ionic liquids and catalysis: Recent progress from knowledge to applications. Appl Catal A, 2010, 373: 1-56

3 Šebesta R, Kmentová I, Toma Š. Catalysts with ionic tag and their use in ionic liquids. Green Chem, 2008, 10: 484-496

4 Mao W, Chan T H. Ionic-liquid-supported synthesis: A novel liquidphase strategy for organic synthesis. Acc Chem Res, 2006, 39: 897908

5 Wong W L, Wong K Y. Recent development in functionalized ionic liquids as reaction media and promoters. Can J Chem, 2012, 90: 1-16

6 Lee S G. Functionalized imidazolium salts for task-specific ionic liquids and their applications. Chem Commun, 2006, 1049-1063

7 Lombardo M, Trombini C. Ionic tags in catalyst optimization: Beyond catalyst recycling. Chem Cat Chem, 2010, 2: 135-145

8 Yang X, Fei Z F, Geldbach T J, et al. Suzuki coupling reactions in ether-functionalized ionic liquids: The importance of weakly interacting cations. Organometallics, 2008, 27: 3971-3977

9 Gao H H, Yan C H, Tao X P, et al. Synthesis of anionic iron(II) complex bearing an $\mathrm{N}$-heterocyclic carbine ligand and its catalysis for aryl Grignard cross-coupling of alkyl halides. Organometallics, 2010, 29: 4189-4192

10 Yan $\mathrm{C} \mathrm{H}$, Wang L L, Gao $\mathrm{H} \mathrm{H}$, et al. An efficient and recyclable iron(III)-containing imidazolium salt catalyst for cross-coupling of aryl Grignard reagents with alkyl halides. Chin Sci Bull, 2012, 57: 19531958

11 Deng H N, Xing Y L, Xia C L, et al. Ionic iron(III) complexes of bis(phenol)-functionalized imidazolium cations: Synthesis, structures and catalysis for aryl Grignard cross-coupling of alkyl Halides. Dalton Trans, 2012, 41: 11597-11607

12 Xia Y, Yan C H, Li Z, et al. Synthesis, structure of iron(III)- containing imidazolium salts and their catalytic activity in the alkylation of aryl Grignard reagents. Chin Sci Bull, 2013, 58: 493-499

13 Tang S K, Baker G A, Zhao H. Ether- and alcohol-functionalized task-specific ionic liquids: Attractive properties and applications. Chem Soc Rev, 2012, 41: 4030-4066

14 Bolm C, Legros J, Paih J L, et al. Iron-catalyzed reactions in organic synthesis. Chem Rev, 2004, 104: 6217-6254

15 Nakamura E, Yoshikai N. Low-valent iron-catalyzed C-C bond formation-addition, substitution, and $\mathrm{C}-\mathrm{H}$ bond activation. J Org Chem, 2010, 75: 6001-6004

16 Liu Q B, Janssen M H A, Rantwijk F V, et al. Room-temperature ionic liquids that dissolve carbohydrates in high concentrations. Green Chem, 2005, 7: 39-42

17 Lund C L, Sgro M J, Cariou R, et al. A cis-bis-mixed-carbene ruthenium hydride complex: An olefin-selective hydrogenation catalyst. Organometallics, 2012, 31: 802-805

18 Avery J S, Burbride C D, Goodume D M L. Raman spectra of tetrahalo-anions of FeIII, MnII, FeII, CuII and ZnII. Spectrochimica Acta, 1968, 24A: 1721-1726

19 Martin R, Fürstner A. Cross-coupling of alkyl halides with aryl Grignard reagents catalyzed by a low-valent iron complex. Angew Chem Int Ed, 2004, 43: 3955-3957

20 Bica K, Gaertner P. An iron-containing ionic liquid as recyclable catalyst for aryl Grignard cross-coupling of alkyl halides. Org Lett, 2006, 8: 733-735

21 Bedford R B, Betham M, Bruce D W, et al. Iron-phosphine, -phosphite, -arsine, and -carbene catalysts for the coupling of primary and secondary alkyl halides with aryl Grignard reagents. J Org Chem, 2006, 71: 1104-1110

22 Fürstner A. From oblivion into the limelight: Iron (domino) catalysis. Angew Chem Int Ed, 2009, 48: 1364

Open Access This article is distributed under the terms of the Creative Commons Attribution License which permits any use, distribution, and reproduction in any medium, provided the original author(s) and source are credited. 